\title{
Adaptive radiotherapy for head and neck cancer
}

\author{
Howard E. Morgan and David J. Sher
}

\begin{abstract}
Background: Although there have been dramatic improvements in radiotherapy for head and neck squamous cell carcinoma (HNSCC), including robust intensity modulation and daily image guidance, these advances are not able to account for inherent structural and spatial changes that may occur during treatment. Many sources have reported volume reductions in the primary target, nodal volumes, and parotid glands over treatment, which may result in unintended dosimetric changes affecting the side effect profile and even efficacy of the treatment. Adaptive radiotherapy (ART) is an exciting treatment paradigm that has been developed to directly adjust for these changes.

Main body: Adaptive radiotherapy may be divided into two categories: anatomy-adapted (A-ART) and responseadapted ART (R-ART). Anatomy-adapted ART is the process of re-planning patients based on structural and spatial changes occurring over treatment, with the intent of reducing overdosage of sensitive structures such as the parotids, improving dose homogeneity, and preserving coverage of the target. In contrast, response-adapted ART is the process of re-planning patients based on response to treatment, such that the target and/or dose changes as a function of interim imaging during treatment, with the intent of dose escalating persistent disease and/or deescalating surrounding normal tissue. The impact of R-ART on local control and toxicity outcomes is actively being investigated in several currently accruing trials.

Conclusions: Anatomy-adapted ART is a promising modality to improve rates of xerostomia and coverage in individuals who experience significant volumetric changes during radiation, while R-ART is currently being studied to assess its utility in either dose escalation of radioresistant disease, or de-intensification of surrounding normal tissue following treatment response. In this paper, we will review the existing literature and recent advances regarding A-ART and R-ART.
\end{abstract}

Keywords: Adaptive radiotherapy, Head and neck squamous cell carcinoma, IMRT, PET-guided radiotherapy, MRIguided radiotherapy

\section{Background}

Over the past 20 years, the standard-of-care for radiotherapy of head and neck squamous cell carcinoma (HNSCC) has transitioned from 2D radiotherapy (RT) to 3D-conformal radiotherapy (3D-CRT) to intensitymodulated radiation therapy (IMRT) [1]. While IMRT has been shown to reduce normal tissue toxicities such as xerostomia [2], its dramatically improved conformality over $2 \mathrm{D}$ and $3 \mathrm{D}-\mathrm{CRT}$ means that anatomic changes in the patient due to weight loss or tumor reduction may have a dramatic impact on the delivered dose.

\footnotetext{
* Correspondence: David.Sher@UTSouthwestern.edu

Department of Radiation Oncology, University of Texas Southwestern Medical Center, 2280 Inwood Rd, Dallas, TX 75390, USA
}

Indeed, many patients will experience volumetric and spatial changes of the target volumes and organs-at-risk (OAR) during treatment, which may be due to some combination of treatment response, weight loss, inflammation, muscle atrophy, and radiation effects on normal tissues. These changes are of significant importance to the dose actually received by the patient, as they are not accounted for on the initial planning scan.

For example, as patients progress through treatment, radiosensitive structures such as the parotids may migrate closer to high dose regions $[3,4]$ resulting in an unintended overdosage which has been associated with worse predicted xerostomia in small retrospective series [3], and target structures may develop dose inhomogeneities with

(c) The Author(s). 2020 Open Access This article is distributed under the terms of the Creative Commons Attribution 4.0 International License (http://creativecommons.org/licenses/by/4.0/), which permits unrestricted use, distribution, and 
unintended cold spots which have been associated with worse local control in non-randomized cohorts $[5,6]$. Sophisticated image guidance technologies such as daily cone-beam computed tomography (CBCT) [7] can account for setup errors between treatment days, but they cannot adjust for inherent changes in the volume and spatial location of the tumor and normal tissues.

In response to this fundamental problem, adaptive radiotherapy (ART) has been developed to address these shortcomings. Adaptive radiotherapy is the process of re-planning patients during treatment either in response to a stimulus, such as weight loss or tumor shrinkage, or at pre-defined intervals over the course of radiation. The process of re-planning allows the radiation plan to adjust to the changing tumor and normal tissue anatomy, reducing dose to sensitive structures such as the parotid glands, while minimizing dose inhomogeneity and inadequate target coverage. In this scenario, ART can be referred to as anatomy-adapted adaptive radiotherapy (A-ART), given ART is guided by structural changes occurring over the course of radiation. In contrast, there has been recent interest in utilizing diagnostic imaging during treatment, such as PET/CT or MRI, to identify treatment response in the primary tumor and/or nodal volumes to guide dose escalation and de-escalation attempts. In this setting, ART can be referred to as response-adapted adaptive radiotherapy (R-ART), since ART is guided by response to therapy. The purpose of this article is to review the existing literature on anatomy- and response-adapted ART.

\section{Main text}

A-ART: impact of volumetric and spatial changes during radiotherapy on delivered dose

Several structures have been shown to change size and shape over the course of radiation for HNSCC, most notably the primary tumor, involved nodes, and the parotid glands. Many retrospective and prospective series have consistently reported decreased tumor size which can be detected as early as the first 2 weeks, with median reported shrinkage rates ranging from 3 to $16 \%, 7$ to $48 \%$ and 6 to $66 \%$ reduction by the end of week $2[8,9]$, 4 [10-16], and 7 [3, 9, 15, 17-28], respectively. Involved nodes can also shrink throughout treatment to similar degrees as the primary tumor $[9,13,14,16,22-25,28]$. Of note, tumor shrinkage during treatment is very heterogenous even within studies, which is not surprising given the known spectrum of radioresponsiveness in HNSCC. For example, one study reported a range of $79.6 \%$ reduction to $-18.8 \%$ increase in primary tumor volume by end of treatment among 34 patients receiving definitive chemoradiotherapy for HNSCC at the Loyola University Medical Center [16]. Another study reported a range of $73 \%$ reduction to $-13 \%$ increase in the high dose clinical target volume (CTV) by the end of treatment in 15 patients receiving definitive chemoradiotherapy for HNSCC [3] in France. For any given patient with a significant volumetric change, though, there may be significant consequences in delivered dose inhomogeneity $[11,15]$, potentially resulting in overdosage of normal tissues or underdosage of the target structures $[18,29]$. See Table 1 for a summary of the volumetric changes of the primary tumor volume in HNSCC over the course of radiotherapy.

In fact, there has been significant interest in the need for ART to improve local control in the definitive treatment of HNSCC $[18,29]$. If ART could correct for these inhomogeneities, then cold spots would be minimized and hypothetically improve in-field failure rates. No randomized data currently exists comparing oncologic outcomes of adaptive and non-adaptive plans to verify this assertation. Retrospective data does appear to suggest a benefit. In a study of 317 patients receiving definitive or adjuvant radiation for HNSCC at UC Davis [5], 51 patients who underwent A-ART per clinical discretion were compared with those who were not re-planned, and there was a significantly higher rate of 2 year localregional control with A-ART ( $88 \%$ vs $79 \%, p=0.01$ ). Of note, all of the local failures within the A-ART group were in-field of the primary PTV. In a separate propensity score matched analysis, 66 patients receiving definitive CRT for T3/T4 NPC with A-ART were matched with 66 patients without A-ART and found that 5 year local-regional recurrence-free survival was higher in those receiving A-ART (96.7\% vs $88.1 \%, p=0.022$ ) [6], but with the major pattern of failure being distant metastases which did not differ significantly between groups. Both of these studies are limited by a lack of standardization of adaptive re-planning specifications and their non-randomized study design. For example, if tumor response was used as a cue to initiate ART, then the use of it would likely select for patients more likely to achieve a partial or complete response following completion of treatment [13].

With respect to OARs, the parotid glands are of particular importance in A-ART, as their radiosensitivity is clearly established, resulting in decreased salivary output at low doses of radiation with associated xerostomia and reduced quality-of-life [30]. In 1999, Eisbruch and colleagues [31] demonstrated that mean doses to the parotid glands as low as $26 \mathrm{~Gy}$ can lead to irreversible xerostomia. With the advent of IMRT, treatment plans were able to spare the parotid glands while still conforming to the target and obtaining adequate coverage. Both contralateral parotid sparing as assessed in PARSPORT I [2] and bilateral superficial parotid sparing methods as assessed in PARSPORT II [32, 33] have shown promising results in regards to minimizing xerostomia following definitive RT for HNSCC. However, not 


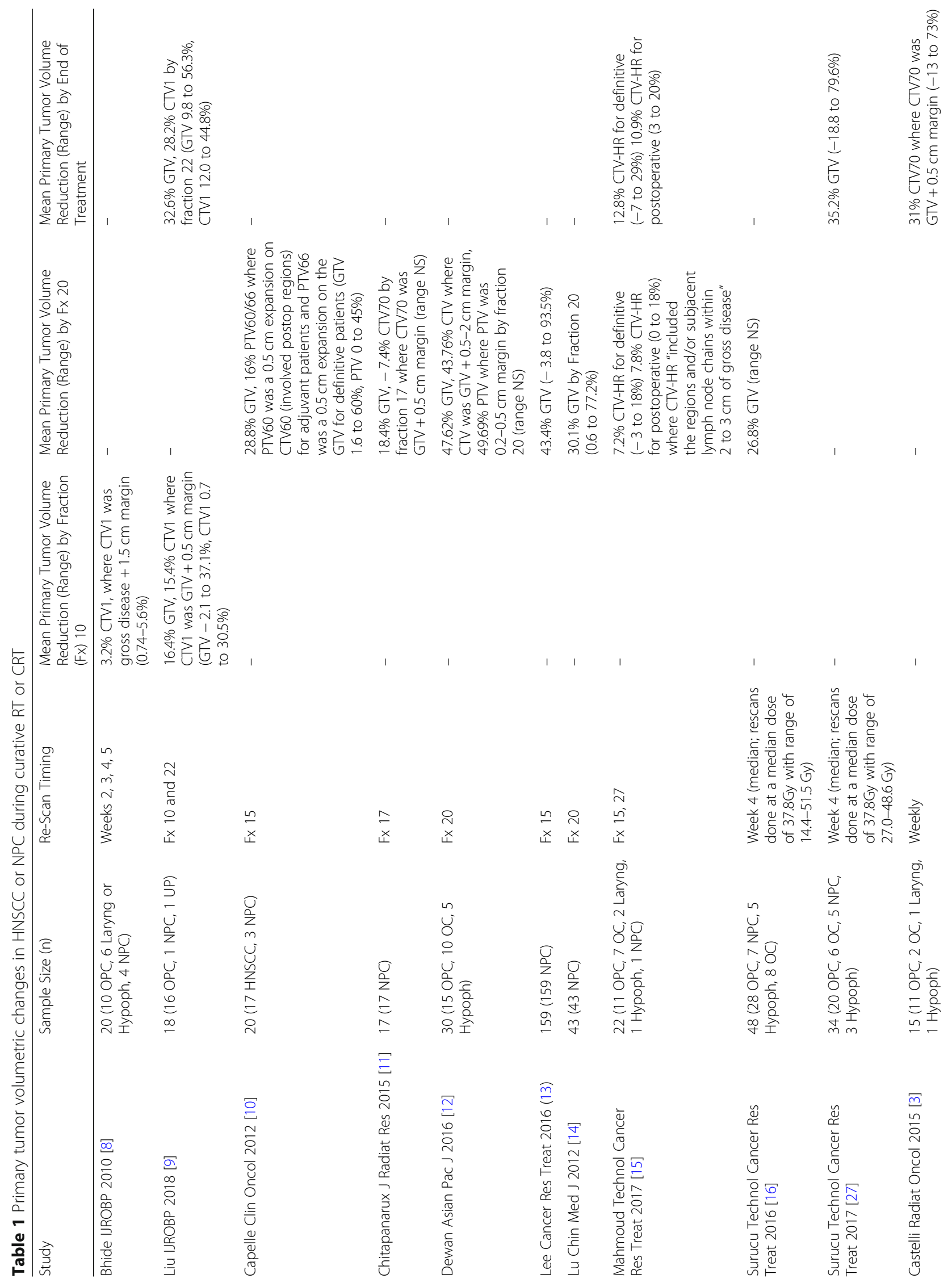




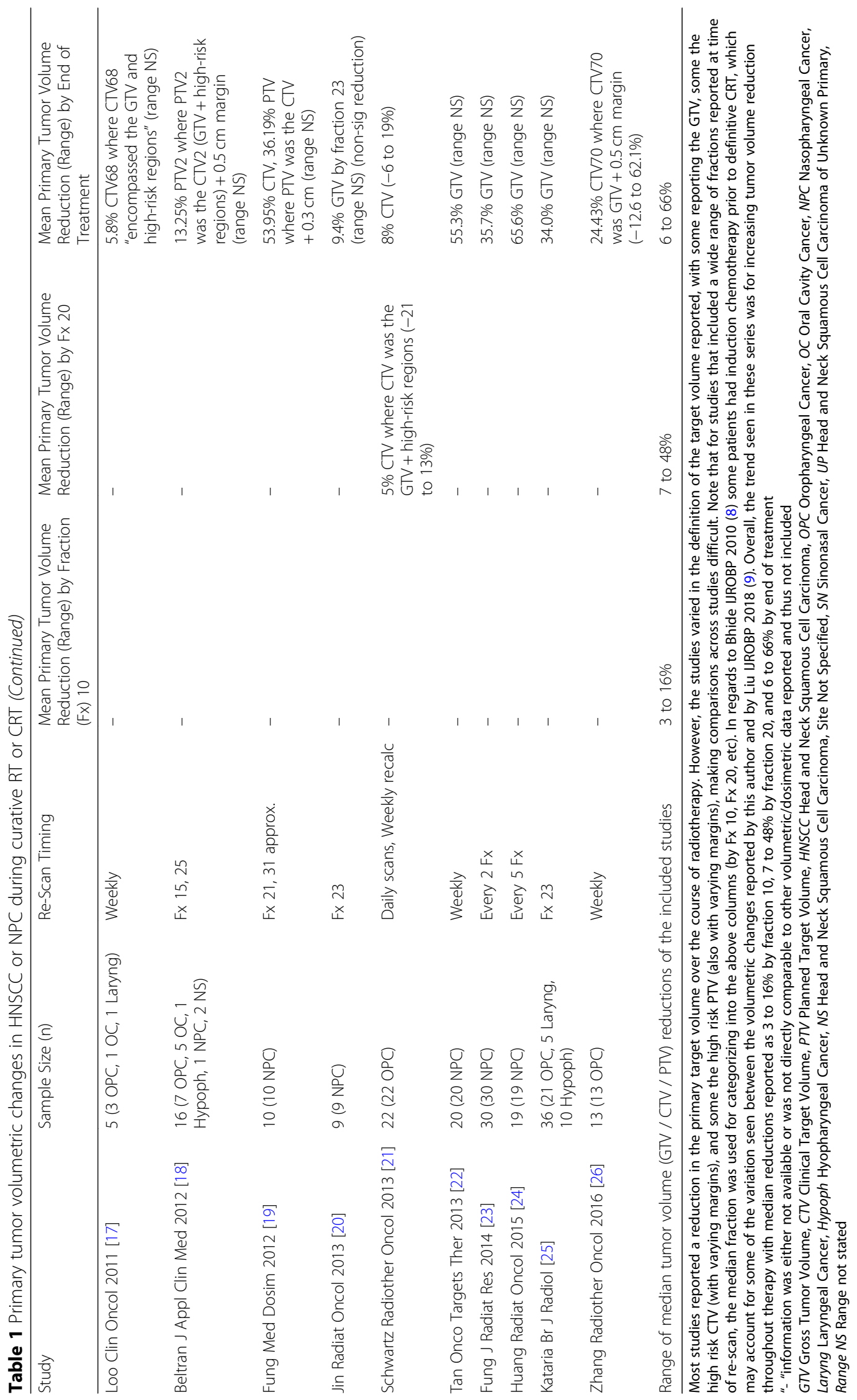


all patients who appear to have excellent sparing of the parotids on treatment planning have excellent rates of xerostomia, as 38\% receiving IMRT in PARSPORT I [2] and $21 \%$ in PARSPORT II still had grade 2 or greater xerostomia by month 12 [32]. Whether this residual xerostomia is fully due to inherent differences in patient response to RT is unclear, but unrecognized (and therefore unadjusted) changes in parotid dosimetry throughout treatment may partially contribute.

Like the primary tumor and involved nodes, the parotid glands have also been consistently reported to shrink throughout treatment, a process that may start as early as the first 2 weeks of treatment. The average volume of the parotids has been reported to decrease as much as $14.7,37$, and $48 \%$ by the end of weeks 2 [8], 4 $[10-12,14,15,18,21,24,34]$, and $7[3,8,11,15,17-21$, $23,24,34-37]$, meaning that the delivered dose could be much higher than expected by the original plan. Like the target volumes, there can also be wide heterogeneity in the volume reduction of parotid glands. One study reported a range of 0.0 to $63.4 \%$ reduction by end of treatment [3] while another reported a range of 6.8 to $69.44 \%$ reduction by end of treatment [36]. This heterogeneity between patients likely contributes to the seemingly contradictory findings between some small studies which predict a xerostomia reduction benefit of A-ART [3, 38] and some studies which do not $[35,39]$. See Table 2 for a summary of volumetric and dosimetric changes of the parotids in HNSCC. Figure 1 is an example of a patient who might benefit from A-ART.

In addition to volume changes, the spatial orientation of the parotid glands appears to shift during treatment, with a typical pattern of superior and medial displacement $[3,4,8,23,24,34]$ thought from shrinkage of the target tumor and associated weight loss. The implication of this shift means that the parotid gland may migrate closer to high-dose regions, resulting in an unplanned overdosage of this structure. In a retrospective cohort of 15 locally advanced HNSCC (primarily oropharyngeal) receiving definitive CRT, Castelli and colleagues [3] noted that $74 \%$ of the parotid glands were an average of $4.3 \mathrm{~mm}$ closer to the CTV by the end of treatment when compared to the initial planning scan. This was associated with an unplanned overdose of $59 \%$ of the parotid glands with an average mean dose increase of $3.7 \mathrm{~Gy}$, with A-ART re-planning reducing the mean parotid dose by 5.1 Gy on average, with a predicted decrease in xerostomia risk of $11 \%$ based on a normal tissue complication probability (NTCP) model [3]. Other studies have also noted increased dose to the parotids with migration medially [24] towards the target [4]. Again, the degree of migration between patients is heterogenous with one study reporting parotid glands moving between $12 \mathrm{~mm}$ closer to the CTV to $6.2 \mathrm{~mm}$ away [3]. Given patients appear to differ fairly broadly in the degree of target shrinkage, parotid volume reduction, and parotid displacement, the subgroup of patients with minimal volumetric and spatial changes over the treatment course would likely gain little from proactive adaptive replanning. Therefore, the identification of a cohort of patients who are most likely to benefit from A-ART is of significant interest to identify the appropriate population for re-planning, as this process is currently laborintensive. Figure 2 shows an example of the relative dosimetric improvement of A-ART.

In addition to the parotid glands, the spinal cord and brainstem are also of interest as hot spots may develop in them over the course of radiotherapy, which may exceed conventional dosimetric constraints, that have been chosen to keep myelopathy and brainstem necrosis rates negligible. Most authors advocate for re-planning when these constraints (spinal cord max dose $<45-48$ Gy and brainstem max dose $<54$ Gy) are breached during radiotherapy. However, studies do not consistently report overdosing of the spinal cord or brainstem with some reporting significant increases in the max dose throughout radiotherapy $[8,10,11,19,24,42]$ and some noting no change [20, 40, 43, 44]. In a prospective cohort study of 22 patients with HNSCC where re-planning was triggered by underdosage of the target volumes (CTV coverage $<95 \%$ ), overdosage of the parotids (mean dose $>26$ Gy), or overdosage of the spinal cord ( $\max$ dose $>45 \mathrm{~Gy}$ ) [15], the spinal cord max dose reached the threshold for triggering A-ART in only 3 of 22 patients, whereas parotid gland overdosages occurred in 3 right and 5 left parotids, and CTV undercoverage in 7 instances. In contrast to the parotids, the volume and position of the spinal cord has not been shown to change over the course of radiotherapy $[17,45]$ which may partially explain why dosimetric changes in the spinal cord and/or brainstem are not as consistent or profound. However, in the studies that do report excess dose to the spinal cord and/or brainstem, dose variation can be quite high with one study reporting a range of $0.2-15.4$ Gy increase in the spinal cord max dose and 0.6-8.1 Gy increase in the brainstem [42] and 2.1-9.9 Gy and 1.6-5.9 Gy respectively in another [11]. Note that a max dose increase of $15 \mathrm{~Gy}$ in the spinal cord can be quite significant, as rates of myelopathy increase exponentially at higher doses, with the estimated risk being $<1 \%$ at 54 Gy and $<$ $10 \%$ at $61 \mathrm{~Gy}$ [46]. In individuals who encounter hot spots in the spinal cord or brainstem during radiotherapy, re-planning has consistently been reported to decrease these max doses back to within their pre-defined thresholds $[11,19,42]$. Though A-ART is beneficial in negating hot spots that may develop in the spinal cord and/or brainstem over the course of radiotherapy, the clinical significance of this is unclear as myelopathy rates 


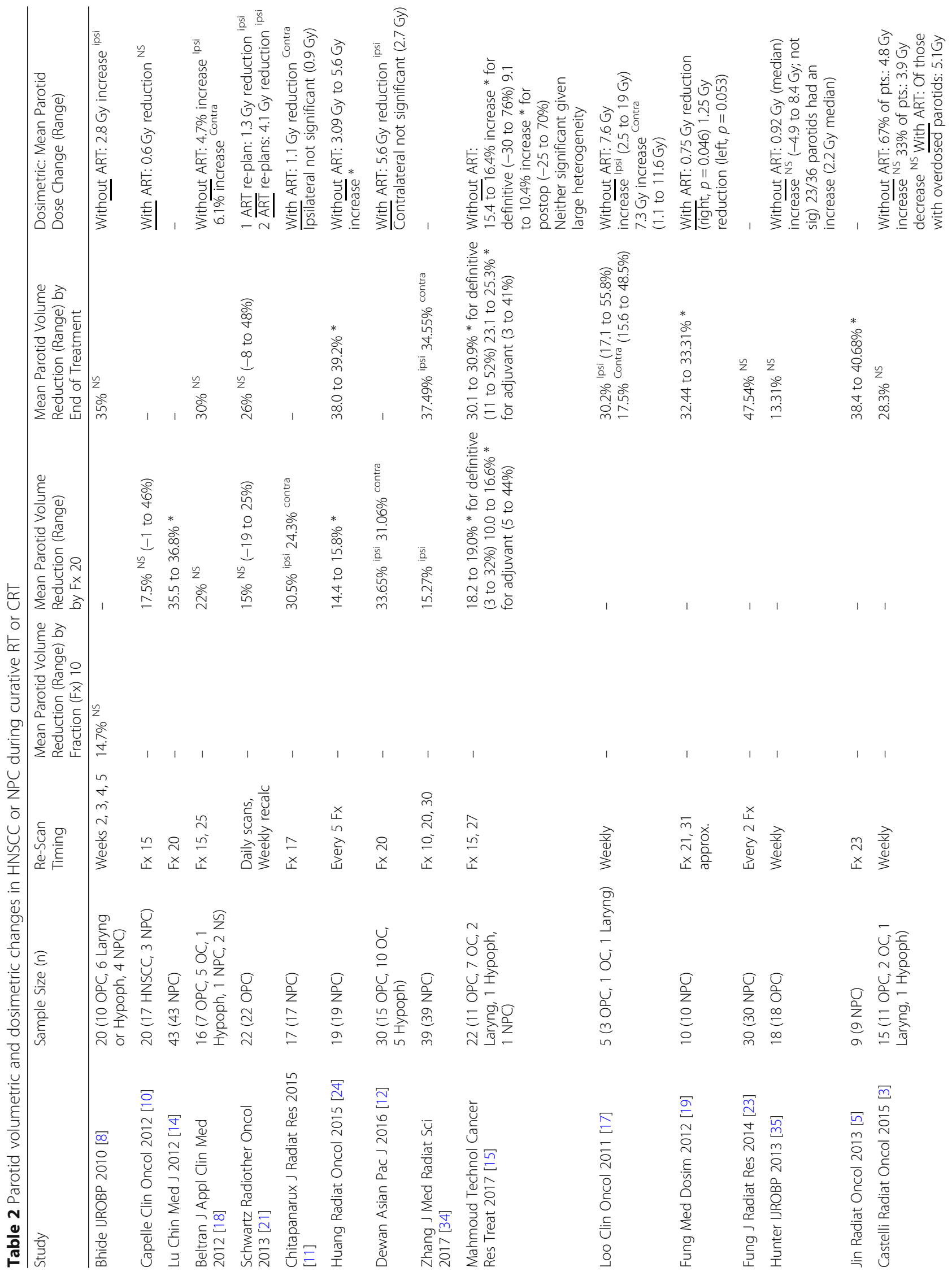




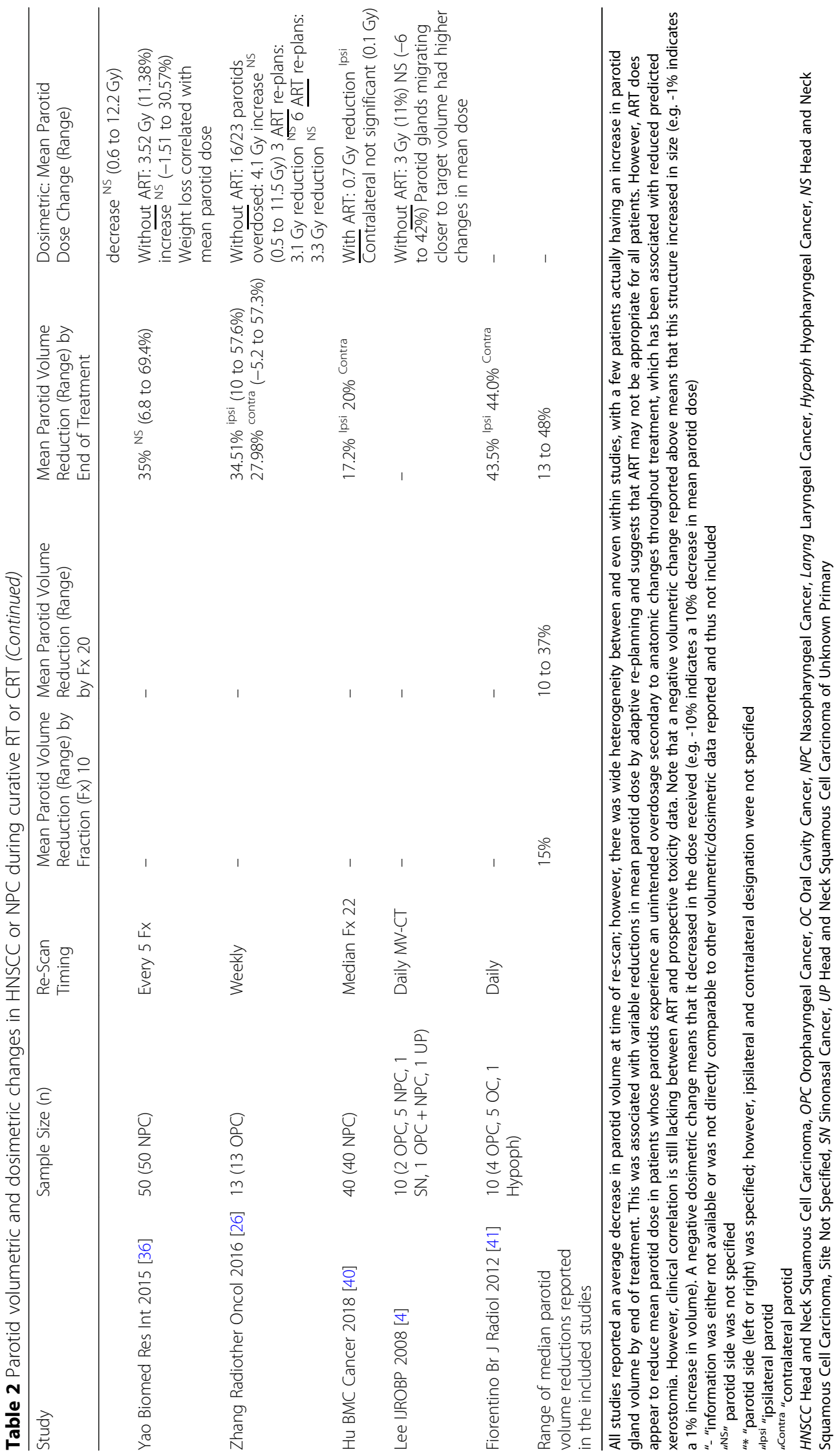




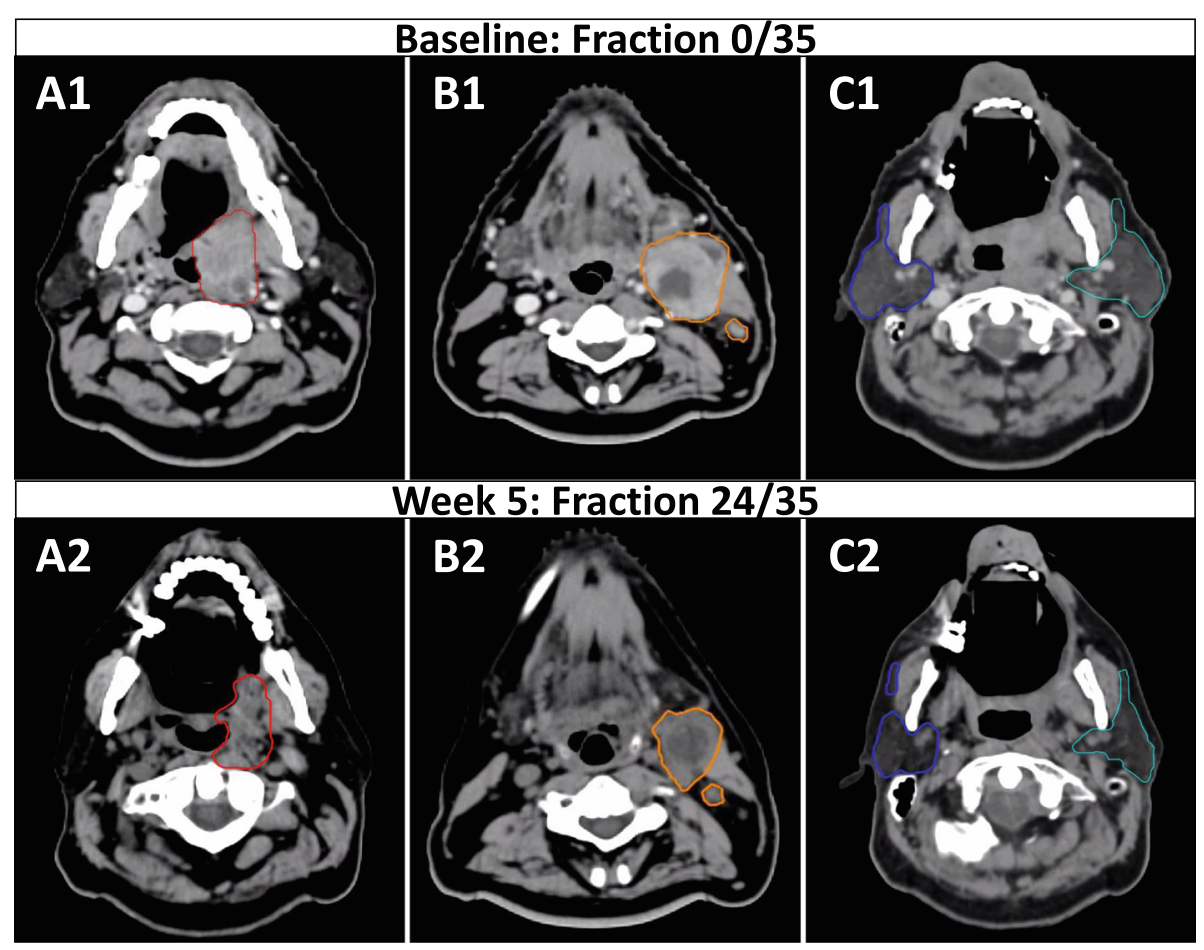

Fig. 1 Primary tumor, nodal, and parotid volumes decrease over the course of radiation. This patient is a 54 year-old man with p16-positive CT4N1M0 squamous cell carcinoma of the left tonsil who required adaptive radiotherapy over the course of radiation secondary to significant tumor response and weight loss during treatment noted on review of daily CBCTs. The primary tumor decreased by $25.0 \%$ from baseline (A 1 ) to week 5 (A2). The grossly involved nodes decreased by 48.6\% from baseline (B1) to week 5 (B2). The left parotid decreased by 37.2\% (cyan) and the right parotid (blue) decreased by $41.9 \%$ from baseline (C1) to week 5 (C2). Note contraction of the lateral border of the bilateral parotids at time of re-simulation (C2)

remain very low in clinical practice. Further, most patients appear to only have modest increases in the spinal cord max dose (2-4Gy) [11, 24, 42] and with several series failing to show a significant overdosage of this structure [20, 40, 43, 44]; clinically significant deviations may only occur in a minority of patients.

The effect of adaptive re-planning on the efficacy and tolerability of postoperative radiation for HNSCC is less clear, given the scarcity of data in this cohort. Some authors have advocated for A-ART in the postoperative setting noting that the postsurgical graft can swell and contract during radiation resulting in under-coverage [5]. However, other studies have questioned the utility of A-ART in the postoperative setting. In a prospective study of 20 patients with HNSCC who were re-planned at fraction 15, the 7 patients receiving postoperative radiation only appeared to have incremental, minimally impactful, changes in dosimetry [10]. Another more recent study prospectively assessed 22 patients with HNSCC but performed CTs for dose recalculation at weeks 1, 3, and 6 to determine the need for A-ART [15]. In this study, 2 of the 11 patients receiving postoperative radiation were re-planned as indicated by critical dosimetric changes by week 6 , with one event triggering A-ART by the development of a spinal cord hot spot and one by CTV underdosage. In contrast, 8 of the 11 in the definitive group with bulky disease (gross tumor $>4 \mathrm{~cm}$ ) encountered at least one event triggering A-ART which was significantly higher than the postoperative group $(p=0.03)$. Given that patients receiving definitive radiation had more weight loss $(8.6 \%$ vs $4.9 \%, p<0.001)$ and a trend towards more high risk CTV shrinkage (12.8\% vs $10.9 \%, p>0.05)$, the authors speculated that target shrinkage and weight loss may help explain the higher incidence of A-ART triggers in the definitive group, though comparisons are limited given the small sample size and lack of clinical correlation with A-ART trigger endpoints. Therefore in the setting of postoperative radiation, because the disease has been resected and the primary driver of anatomic change appears to be weight loss rather than tumor shrinkage, A-ART appears to be needed less frequently in patients treated with adjuvant RT.

Recently, MRI-guided radiotherapy has been evaluated for its utility in A-ART $[47,48]$, with the idea that adaptive scans utilizing MRI imaging can dramatically improve visualization of soft tissue changes throughout 

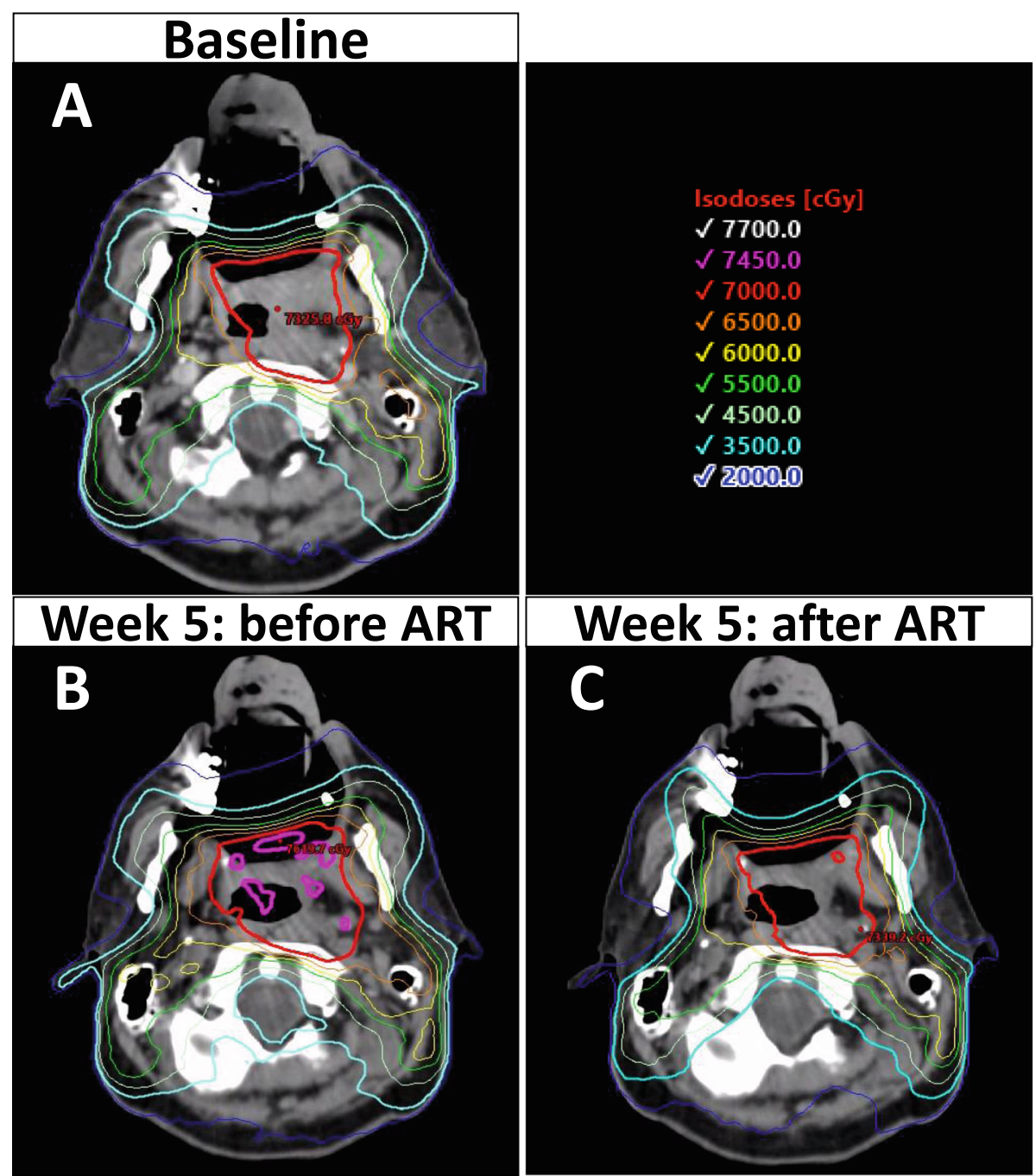

Fig. 2 Adaptive re-planning reduces unplanned dose inhomogeneity and parotid gland overdose. These images are from the same case as presented in Fig. 1. At time of initial simulation (a), anticipated coverage of the high dose planned target volume (PTV) was 98.5\% receiving 70Gy and the mean dose of the left and right superficial parotids were 25.0 and $24.5 \mathrm{~Gy}$, respectively. However, by week 5 (b), there was wide variation in dose within the high dose PTV with cold spots down to $88.0 \%$ and hot spots up to $113.4 \%$ of the prescription. In addition, the mean left and right superficial parotids doses increased to $32.2 \mathrm{~Gy}$ and $36.7 \mathrm{~Gy}$, respectively. With adaptive re-planning (c), dose homogeneity was improved with cold spots only being $94.8 \%$ and hot spots only being $104.4 \%$ inside of the high dose PTV, with reduction of the mean right and left superficial parotid dose back to $24.9 \mathrm{~Gy}$ and $24.6 \mathrm{~Gy}$, respectively. The main benefit of A-ART in this case was sparing of the parotids, given there was an unplanned overdose of an additional 7.2 Gy to the left and 12.2 Gy to the right parotids which was mitigated with adaptive re-planning

treatment. In a prospective feasibility study at MD Anderson Cancer Center [48], five patients with locally advanced HPV-positive OPC underwent definitive CRT, with intra-treatment MRI every 2 weeks. The primary gross tumor volume (GTV) volume was noted to decrease on average by 44,90 , and $100 \%$ at weeks 2,4 , and 6 , with the corresponding nodal volumes decreasing by 25,60 , and $80 \%$. The high dose target volume was reduced accordingly with these volumetric changes, resulting in an approximate reduction in the mean parotid dose of $3.3 \mathrm{~Gy}$ with ART. Although NTCP modeling only predicted a $1 \%$ xerostomia reduction at 6 months, the probability of predicted 6 month dysphagia was reduced by $11 \%$ [48]. The high rates of radiographic complete response (CR) on MRI of the primary tumors in this study are congruent with a prior pilot trial by the same group where 15 out of 29 primary tumors had a CR detected on MRI imaging at 3-4 weeks [47]. A separate group reported $70 \%$ average GTV reduction on MRI imaging by week 6 in eight patients with OPC [49]. The MARTHA trial is an upcoming prospective trial attempting to assess if the use of daily MRI imaging and weekly plan adaptation will benefit xerostomia in patients receiving RT for HNSCC [50]. 


\section{A-ART: practical considerations and implementation}

Currently, the process of A-ART requires (1) identifying the appropriate patient, (2) re-simulation, (3) re-contouring, and (4) re-planning. Patients may be identified for A-ART by clinical variables (weight loss, tumor shrinkage, etc); regularly planned intervals; treatment response as assessed on CBCT scans, diagnostic CT or MRI scans; or dose recalculations of cumulative dose delivered to the targets and OARs. Following identification, re-simulation of the patient should occur promptly, which may require creation of a new aquaplastic/thermoplastic mask if the mask fit is inadequate. Then, re-contouring can be done via manual input from the physician, deformable image registration, or automatic segmentation. Artificial intelligence methods of auto-contouring are being developed to make this process more efficient. If deformable image registration or an automatic method are used for re-contouring, it is recommended that the physician proofread these contours for errors prior to approval. The plan is then re-planned and optimized per physician discretion.

One of the biggest obstacles with adaptive re-planning is the time required to manually re-simulate, re-contour, and re-plan patients, which can be draining on a department's resources; developing an optimal trigger for implementing A-ART is therefore a high priority to maximize efficiency. At this time, no consensus exists on the most appropriate timing regimen for A-ART during radiotherapy. Many centers perform adaptive re-planning based on clinical characteristics, such as weight loss, tumor shrinkage, changes in patient setup, and mask fitting. Other approaches suggest performing A-ART at regular intervals (e.g. every 10 fractions), as reductions in target and parotid volumes have been shown to occur as early as the first or second week which can result in significant dosimetric changes [24, 26]. In a study assessing the timing of AART scans in 13 patients with OPC receiving definitive radiation [26], weekly CT scans were performed and assessed for a dosimetric benefit of A-ART re-planning at each interval. They found 3 re-plans (weeks 1, 2, and 5) to be comparable with 6 weekly re-plans estimating a mean parotid gland benefit of 3.1 Gy with 3 re-plans compared with only $3.3 \mathrm{~Gy}$ if 6 . The majority of the benefit appeared to be within the first 2 weeks, with the authors recommending A-ART at weeks 1,2 , and 5 [26]. In a separate study of 19 patients with NPC receiving definitive radiation with weekly $\mathrm{CT}$ scans, significant dosimetric variations in the target, parotids, spinal cord, and brainstem were noted mostly at fractions 5 and 15, with the authors recommending A-ART re-plans at these time points [24].

Given the wide range of variability in anatomic changes of the target structures and OARs between patients throughout radiation (as discussed in the previous section), we advocate that $1 \mathrm{~A}$-ART regimen is not likely applicable to all patients. Some studies have attempted to identify baseline and dosimetric factors influencing the likelihood of a patient needing A-ART during their treatment course, with the most common factors identified being: higher initial mean parotid gland dose [36, 38, 51], larger clinical target volumes (CTV) and bulkier disease $[15,38,52]$, initial weight [52], and a faster rate of weight loss [36]. Most of these predictive variables have not been validated. However, one study assessed initial mean parotid dose $>22.2 \mathrm{~Gy}$ as a cutoff value in a validation cohort of 43 patients, but the positive predictive value was only $19 \%$ with a sensitivity of $80 \%$ [51], suggesting most patients meeting this criteria still would not benefit from A-ART, resulting in significant clinic inefficiencies.

Recent advances have looked at individualizing indications for A-ART by recalculating the cumulative dose of the target and OAR every day or every week to identify actionable changes in dosimetry which may necessitate re-planning [53, 54]. In an initial pilot study of A-ART at MDACC, Schwartz and colleagues [55] prospectively evaluated 22 patients with oropharyngeal SCC receiving definitive radiation with weekly CT dose recalculations to prompt A-ART re-planning if target coverage was poor or if OAR sparing was inadequate. All 22 patients had at least 1 adaptive re-plan and 8 had 2 re-plans with this approach. On dosimetric analysis, the ipsilateral parotid dose was reduced by $1.3 \mathrm{~Gy}(p=0.002)$ in those receiving 1 re-plan and 4.1 Gy in those receiving 2 re-plans [21]. In a separate prospective study also utilizing weekly CT scans in patients receiving definitive RT for HNSCC [56], patients were selected for A-ART if their recalculated plan on their weekly CT scan yielded a PTV70 or PTV60 receiving V $95<95 \%$ or spinal cord receiving max dose $\geq 45$ Gy. This method resulted in 8 out of 10 patients being re-planned with A-ART, with $41 \%$ of the replans triggered in the first 2 weeks. While these early studies have predominantly used weekly CT scans, there has been recent effort to improve efficiency by utilizing CBCTs used in the daily delivery of radiation to calculate the cumulative dose received [53, 57-59] allowing the prompt identification of patients likely to benefit from AART. As technology and artificial intelligence advances, we anticipate that the identification of patients and the implementation of A-ART will be significantly smoother and likely automated. Table 3 describes currently accruing and upcoming trials in A-ART.

\section{Response-adapted adaptive radiotherapy (R-ART)}

In contrast to A-ART, in which the subsequent radiation re-plan essentially recapitulates the original radiation targets and doses adapted to the new anatomy, responseadapted ART is the process of changing the radiation targets and/or doses based on response to treatment. Whether the "response" is identified by CT, PET-CT, or MRI, the intent of R-ART is to either escalate the 
Table 3 Currently accruing or upcoming clinical trials in anatomy-adapted adaptive radiotherapy (A-ART)

\begin{tabular}{|c|c|c|c|c|c|}
\hline Clinical Trial & $\begin{array}{l}\text { Primary Investigator } \\
\text { (Location) }\end{array}$ & Description & Eligible & $\begin{array}{l}\text { Target Accrual } \\
\text { (Actual or Current } \\
\text { Accrual) }\end{array}$ & Status \\
\hline $\begin{array}{l}\text { Evaluation of the } \\
\text { Automatic Deformable } \\
\text { Recontouring on the } \\
\text { Daily MVCT for Head } \\
\text { and Neck Cancer } \\
\text { Adaptive Radiotherapy } \\
\text { (GIRAFE) }[45,60]\end{array}$ & $\begin{array}{l}\text { Laprie Anne } \\
\text { (Institut Universitaire } \\
\text { Du Cancer Toulouse, } \\
\text { Oncopole, France) }\end{array}$ & $\begin{array}{l}\text { Prospective phase II trial } \\
\text { evaluating the accuracy } \\
\text { of deformable image } \\
\text { registration on daily } \\
\text { MV-CTs. Deformable } \\
\text { image registration will } \\
\text { be compared to manual } \\
\text { recontouring on weeks } \\
3,4,5 \text {, and } 6 \text {. } \\
\text { Primary Outcome: Dice } \\
\text { similarity coefficient } \\
\text { Implication: if } \\
\text { deformable image } \\
\text { registration is reliable, } \\
\text { may help streamline } \\
\text { A-ART and assist with } \\
\text { identification of those } \\
\text { who would benefit }\end{array}$ & $\begin{array}{l}\text { T3-4 and/or } \\
\text { node }>2 \mathrm{~cm} \\
\text { HNSCC receiving } \\
\text { definitive RT }\end{array}$ & 48 & $\begin{array}{l}\text { Not yet recruiting } \\
\text { (as of July } 25,2019 \text { ) }\end{array}$ \\
\hline $\begin{array}{l}\text { A Prospective Non- } \\
\text { Inferiority Trial of the } \\
\text { Use of Adaptive } \\
\text { Radiotherapy for } \\
\text { Head and Neck Cancer } \\
\text { Undergoing Radiation } \\
\text { Therapy [45] }\end{array}$ & $\begin{array}{l}\text { Jillian Tsai, MD } \\
\text { (Memorial Sloan } \\
\text { Kettering Cancer } \\
\text { Center) }\end{array}$ & $\begin{array}{l}\text { Prospective trial } \\
\text { comparing LRFS in } \\
\text { those receiving ART } \\
\text { to historical controls } \\
\text { with the intent of } \\
\text { assessing non-inferiority } \\
\text { Primary Outcome: } \\
\text { LRFS at } 2 \text { years }\end{array}$ & $\begin{array}{l}\text { HNSCC receiving } \\
\text { definitive RT }\end{array}$ & $65[61]$ & $\begin{array}{l}\text { Active, not recruiting } \\
\text { (as of May 27, 2019) }\end{array}$ \\
\hline $\begin{array}{l}\text { MRI-guided Adaptive } \\
\text { RadioTHerapy for } \\
\text { reducing xerostomiA } \\
\text { in Head and Neck } \\
\text { Cancer (MARTHA-trial) [50] }\end{array}$ & $\begin{array}{l}\text { Panagiotis Balermpas, MD } \\
\text { (University Hospital Zurich) }\end{array}$ & $\begin{array}{l}\text { Prospective trial of } \\
\text { MRI-guided IGRT with } \\
\text { daily MRI imaging and } \\
\text { weekly plan adaptation, } \\
\text { with the objective of } \\
\text { evaluating xerostomia } \\
\text { by LENT-SOMA } \\
\text { and salivary flow } \\
\text { measurements at } \\
\text { baseline, } 6,12 \text {, and } \\
24 \text { months } \\
\text { Primary Outcome: } \\
12 \text { month grade } 2 \text { or } \\
\text { worse xerostomia }\end{array}$ & $\begin{array}{l}\text { Stages } \| \text { IIVb HNSCC } \\
\text { receiving definitive RT }\end{array}$ & 44 & Not yet recruiting \\
\hline
\end{tabular}

radiotherapy dose to persistent disease or reduce the dose to responding disease, leading to improved tumor control and/or reduced normal tissue toxicity.

Given that in-field recurrences are still a common pattern-of-failure in HNSCC [62-64], further treatment intensification is still needed in some patient populations, with radiation dose escalation serving as one possible paradigm. Response-adapted ART is an attractive avenue for dose escalation, since persistent or refractory disease during treatment may be directly targeted, effectively reducing the volume of disease being boosted. For example, PET-guided ART is under active investigation, with persistent radiotracer uptake early in treatment thought to represent radioresistance. Both standard tracers such as [18F]Fluoro-2-deoxy-2-D-glucose (FDG) $[65,66]$ and more novel indicators of hypoxia such as [18F]Fluoroazomycin-arabinoside (FAZA) [61, 67] are being studied.
Oncologic outcomes with PET-based R-ART is limited, but preliminary reports suggest that such a paradigm is feasible $[68,69]$. In an initial phase I feasibility trial at Ghent University Hospital [68], the radiotherapy dose was escalated to over $80 \mathrm{~Gy}$ to areas of persistent avidity on a PET-CT scan performed during week 2 . No acute dose-limiting toxicity was encountered. Although randomized evidence is not yet available, a recent casematched control study [70] compared 72 patients treated on this study or similar subsequent trials receiving 70.285.5Gy to those receiving standard IMRT did not find a statistically significant difference in 5 year local control (82.3\% vs $73.6 \%, p=0.36)$. However, this retrospective analysis did note increased chronic toxicity at higher doses, with late grade $\geq 3$ dysphagia being $50 \%$ (vs $28 \%$, $p=0.004$ ) and with grade 4 mucosal ulcers occurring at the site of dose escalation in $13 \%$ (9/72) of patients [70]. The incidence of these late grade 4 mucosal ulcers was 
correlated with both higher hotspots in the plan (84 Gy was an identified threshold) as well as continued smoking or alcohol use following therapy [71].

It is still an open question whether dose-escalation is a reasonable approach to improve locoregional control in HNSCC, especially in this new era of immunotherapy. Although increased toxicity with dose escalation is anticipated, whether the potential for improved locoregional control counterbalances potentially serious mucosal complications remains to be seen. Fortunately, several randomized phase II trials are currently attempting to answer this question. The C-ART-2 study is a randomized phase II trial at the University Hospital of Ghent comparing its institutional R-ART dose-escalation technique (R-ART based on interim PET-CT during treatment) with standard chemoradiotherapy, with the primary endpoint being locoregional control [72]. ARTFORCE is a multiinstitutional randomized phase II trial assessing if PET-guided dose-escalation to $84 \mathrm{~Gy} / 35 \mathrm{Fx}$ improves locoregional control in comparison to standard RT 70Gy/35Fx. This study uses PET to develop the initial dose-escalation volume but the adaptation is actually strictly based on CT-only changes at week $2[73,74]$.

In contrast to dose-escalation approaches to R-ART, a separate treatment philosophy is to use interim diagnostic imaging to guide dose de-intensification in responders, with the goal to improve the acute and chronic toxicity profile of HNSCC RT. Preliminary work on correlating interim PET-CT tumor response to local-regional failure free survival (LRFS) has demonstrated that, in general, patients who have a more pronounced metabolic response by mid-treatment scan appear to have better long-term locoregional control [75-77]. These non-intervention studies have generated the exciting concept that interim PET-CT can select robust responders for dose de-intensification strategies, but no prospective data are yet available to prove the viability of this paradigm. An upcoming phase II feasibility study, entitled PEARL, will be assessing if dose de-intensification of surrounding normal tissues can safely be executed with the use of an intra-treatment $\mathrm{PET} / \mathrm{CT}$ at 2 weeks to guide reduction in target volumes as the tumor responds [78].

A separate approach is to harness the superior soft tissue definition of MRI imaging to continuously adapt and shrink the high-dose treatment volume to MRI-visible disease $[47,48]$. Initial pilot trials utilizing intratreatment MRI imaging in patients with OPC receiving definitive CRT have demonstrated high CR rates during treatment, with one reporting $51.7 \% \mathrm{CR}$ of the primary by week 3-4 [47], a second reporting 90 and $100 \%$ volume reduction by weeks 4 and 6 [48], and a third reporting 70\% GTV reduction by week 6 [49]. These rates of tumor shrinkage appear higher than what has been historically reported in separate studies using CT-based intra-treatment scans (see Table 1). This has led to interest of whether MRI-guided R-ART may help guide further shrinkage of high dose target volumes. However, some concern has been raised over whether limiting the target volumes to only the shrinking MRI-visible disease may hurt local control, as it has been hypothesized that at least some of the tumor may be dissolving instead of shrinking, leaving behind microscopic disease in areas previously occupied by the tumor. In a small study of 8 patients with locally advanced OPC receiving definitive CRT, fiducials were placed around the outer edge of the primary tumors and patients had repeat MRIs done during weeks 3 and 6 of CRT. They found that the GTV as detected on MRI reduced in size more than the displacement of the fiducials (absolute difference of 0.1 and 0.3 $\mathrm{cm}$ at weeks 3 and 6 , respectively) supporting the hypothesis that some of the tumor may be dissolving [49]; this finding implies that the area previously occupied by the tumor on baseline scans may still require low dose radiation sufficient to eradicate microscopic disease. The MR-ADAPTOR trial is a currently accruing phase II study that is assessing if weekly MRI imaging can be safely used to guide adaptation of the high risk target volumes whilst maintaining coverage of the areas previously occupied by disease with at least $50.16 \mathrm{~Gy}$, with the primary endpoint being determination if 6 month LRC is similar to standard non-adapted IMRT [37, 79]. Table 4 details currently accruing and upcoming trials regarding R-ART.

\section{Conclusions}

Although significant advances in radiation delivery and image guidance have led to clear improvements in quality-of-life following head and neck radiotherapy, these methods do not account for volumetric and spatial changes that occur throughout treatment, sometimes as early as week 2. Anatomy-adapted adaptive radiotherapy (A-ART) offers a way to counteract these changes, achieving maintenance of target coverage and avoiding OAR overdosage, by re-simulating and re-planning patients either in response to a clinical or dosimetric signal or at regularly timed intervals. Currently, there is no consensus on the most appropriate way to incorporate A-ART into clinical practice. Noting the wide heterogeneity in volume and spatial changes of targets and OARs across patients, A-ART may be futile for those with minimal anatomic change, while it could be instrumental in dosimetric optimization in those with more pronounced changes. However, randomized evidence is not yet available to confirm a clinical benefit. Given the time burden required to re-plan patients and the low yield of A-ART for a subgroup of patients without much 


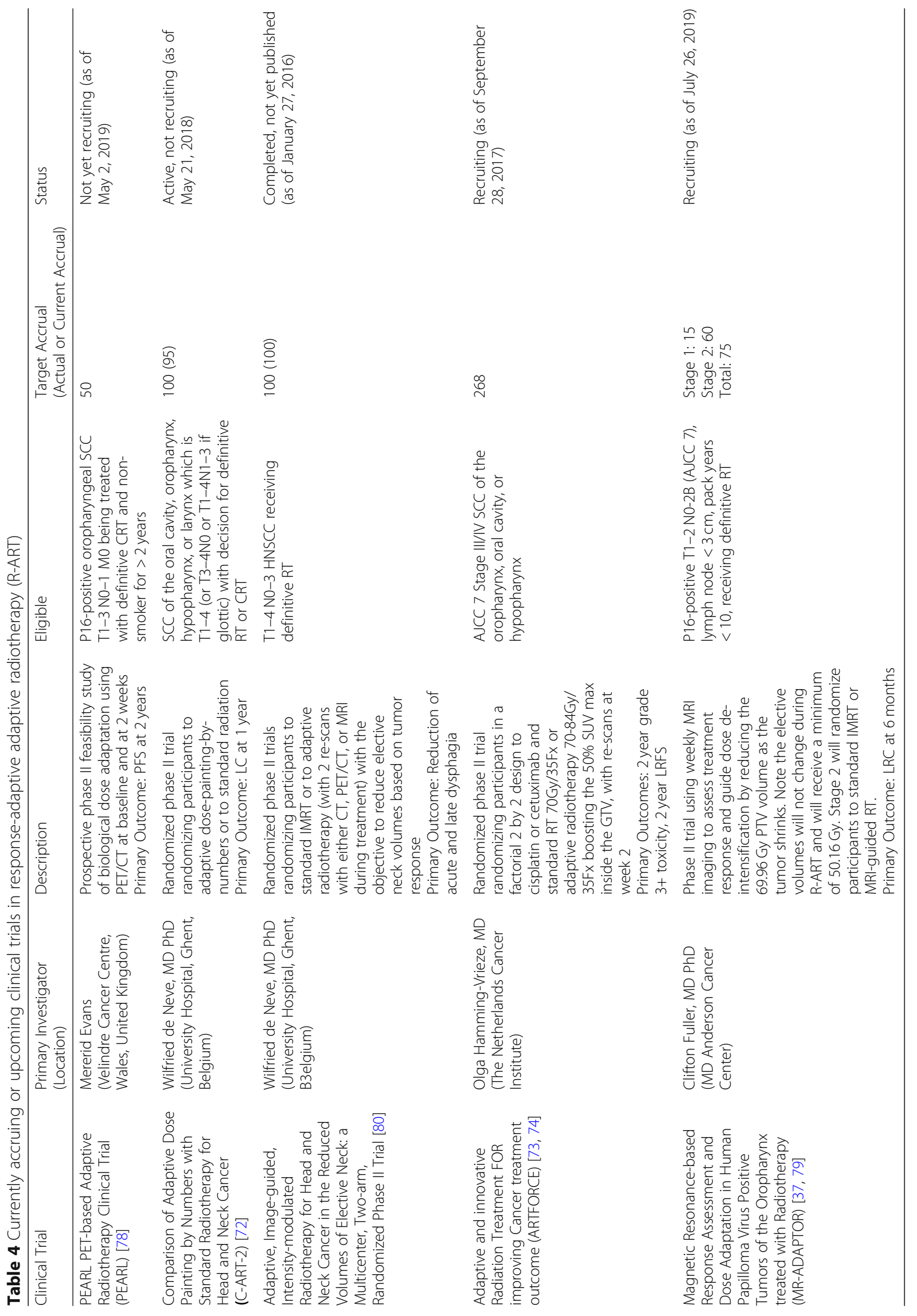


anatomic change, the identification of individuals who would most benefit is an area of active research. Perhaps, most promising is the development of automated methods for calculating cumulative dose received by the targets and OARs to identify candidates for A-ART. Soon even clinical re-planning will be feasible based on each CBCT [81], so that A-ART can be entirely automated. In fact, if daily adaptive re-planning becomes more automated and streamlined, planning target volume (PTV) expansions currently used for setup uncertainty could be significantly reduced, minimizing normal tissue doses from day one.

Response-adapted adaptive radiotherapy (R-ART) has been the subject of more recent prospective investigations and holds the promise of using novel technologies to improve tumor control and/or the acute and late tolerance of radiotherapy. Several trials utilizing R-ART should mature over the next several years and may help discern whether such an approach is worth further pursuit. In principle, response-adapted ART may further improve the therapeutic ratio in a disease site whose normal tissue structures are intrinsically entangled with the targets for irradiation.

\section{Abbreviations}

A-ART: Anatomy-adapted Adaptive Radiotherapy; ART: Adaptive Radiotherapy; CBCT: Cone-Beam CT; CR: Complete Response; CT: Computed Tomography; CTV: Clinical Target Volume; FAZA: [18F]Fluoroazomycinarabinoside; FDG: [18F]Fluoro-2-deoxy-2-D-glucose; Fx: Fraction; GTV: Gross Tumor Volume; HNSCC: Head and Neck Squamous Cell Carcinoma; Hypoph: Hyopharyngeal Cancer; IMRT: Intensity-Modulated Radiation; Laryng: Laryngeal Cancer; MRI: Magnetic Resonance Imaging; NPC: Nasopharyngeal Cancer; NPC: Nasopharyngeal Carcinoma; NS: Head and Neck Squamous Cell Carcinoma, Site Not Specified; OAR: Organ at Risk; OC: Oral Cavity Cancer; OPC: Oropharyngeal Cancer; PTV: Planned Target VolumeR-ARTResponse-adapted Adaptive Radiotherapy; SN: Sinonasal Cancer; UP: Head and Neck Squamous Cell Carcinoma of Unknown Primary

\section{Acknowledgments}

Not applicable.

\section{Authors' contributions}

Both authors wrote, read, and approved the final manuscript

Authors' information

Not applicable.

Funding

There was no funding required for this review article.

Availability of data and materials

Not applicable.

Ethics approval and consent to participate

Not applicable.

\section{Consent for publication}

Consent for publication was provided by the individual presented in Figs. 1 and 2. Following informed consent, he signed the BioMed Central consent form.

\section{Competing interests}

The authors declare that they have no competing interests.
Received: 20 August 2019 Accepted: 11 November 2019

Published online: 09 January 2020

\section{References}

1. (NCCN) NCCN. NCCN clinical practice guidelines in oncology: head and neck cancers (version 2.2019) 2019 [updated 6/28/2019. Available from: https://www.nccn.org/professionals/physician_gls/pdf/head-and-neck.pdf.

2. Nutting CM, Morden JP, Harrington KJ, Urbano TG, Bhide SA, Clark C, et al. Parotid-sparing intensity modulated versus conventional radiotherapy in head and neck cancer (PARSPORT): a phase 3 multicentre randomised controlled trial. Lancet Oncol. 2011;12(2):127-36.

3. Castelli J, Simon A, Louvel G, Henry O, Chajon E, Nassef M, et al. Impact of head and neck cancer adaptive radiotherapy to spare the parotid glands and decrease the risk of xerostomia. Radiat Oncol. 2015;10:6.

4. Lee C, Langen KM, Lu W, Haimerl J, Schnarr E, Ruchala KJ, et al. Assessment of parotid gland dose changes during head and neck cancer radiotherapy using daily megavoltage computed tomography and deformable image registration. Int J Radiat Oncol Biol Phys. 2008;71(5):1563-71.

5. Chen AM, Daly ME, Cui J, Mathai M, Benedict S, Purdy JA. Clinical outcomes among patients with head and neck cancer treated by intensity-modulated radiotherapy with and without adaptive replanning. Head Neck. 2014;36(11): $1541-6$.

6. Luo Y, Qin Y, Lang J. Effect of adaptive replanning in patients with locally advanced nasopharyngeal carcinoma treated by intensity-modulated radiotherapy: a propensity score matched analysis. Clin Transl Oncol. 2017; 19(4):470-6.

7. Ciardo D, Alterio D, Jereczek-Fossa BA, Riboldi M, Zerini D, Santoro L, et al. Set-up errors in head and neck cancer patients treated with intensity modulated radiation therapy: quantitative comparison between threedimensional cone-beam $\mathrm{CT}$ and two-dimensional kilovoltage images. Phys Med. 2015;31(8):1015-21

8. Bhide SA, Davies M, Burke K, McNair HA, Hansen V, Barbachano Y, et al. Weekly volume and dosimetric changes during chemoradiotherapy with intensity-modulated radiation therapy for head and neck cancer: a prospective observational study. Int J Radiat Oncol Biol Phys. 2010;76(5): 1360-8.

9. Liu Q, Liang J, Zhou D, Krauss DJ, Chen PY, Yan D. Dosimetric evaluation of incorporating patient geometric variations into adaptive plan optimization through probabilistic treatment planning in head and neck cancers. Int J Radiat Oncol Biol Phys. 2018;101(4):985-97.

10. Capelle L, Mackenzie M, Field C, Parliament M, Ghosh S, Scrimger R. Adaptive radiotherapy using helical tomotherapy for head and neck cancer in definitive and postoperative settings: initial results. Clin Oncol (R Coll Radiol). 2012;24(3):208-15.

11. Chitapanarux I, Chomprasert K, Nobnaop W, Wanwilairat S, Tharavichitkul E, Jakrabhandu S, et al. A dosimetric comparison of two-phase adaptive intensity-modulated radiotherapy for locally advanced nasopharyngeal cancer. J Radiat Res. 2015;56(3):529-38.

12. Dewan A, Sharma S, Dewan A, Srivastava H, Rawat S, Kakria A, et al. Impact of adaptive radiotherapy on locally advanced head and neck Cancer - a Dosimetric and volumetric study. Asian Pac J Cancer Prev. 2016;17(3):985-92.

13. Lee H, Ahn YC, Oh D, Nam H, Noh JM, Park SY. Tumor volume reduction rate during adaptive radiation therapy as a prognosticator for nasopharyngeal Cancer. Cancer Res Treat. 2016:48(2):537-45.

14. Lu N, Feng LC, Cai BN, Hou J, Wang YL, Xie CB. Clinical study on the changes of the tumor target volume and organs at risk in helical tomotherapy for nasopharyngeal carcinoma. Chin Med J. 2012;125(1):87-90.

15. Mahmoud O, Reis IM, Samuels MM, Elsayyad N, Bossart E, Both J, et al. Prospective pilot study comparing the need for adaptive radiotherapy in Unresected bulky disease and in postoperative patients with head and neck Cancer. Technol Cancer Res Treat. 2017;16(6):1014-21.

16. Surucu M, Shah KK, Mescioglu I, Roeske JC, Small W Jr, Choi M, et al. Decision trees predicting tumor shrinkage for head and neck Cancer: implications for adaptive radiotherapy. Technol Cancer Res Treat. 2016;15(1): 139-45.

17. Loo H, Fairfoul J, Chakrabarti A, Dean JC, Benson RJ, Jefferies SJ, et al. Tumour shrinkage and contour change during radiotherapy increase the dose to organs at risk but not the target volumes for head and neck cancer patients treated on the TomoTherapy HiArt system. Clin Oncol (R Coll Radiol). 2011;23(1):40-7. 
18. Beltran M, Ramos M, Rovira JJ, Perez-Hoyos S, Sancho M, Puertas E, et al. Dose variations in tumor volumes and organs at risk during IMRT for headand-neck cancer. J Appl Clin Med Phys. 2012;13(6):3723.

19. Fung WW, Wu WW, Teo PM. Dosimetric evaluation of a three-phase adaptive radiotherapy for nasopharyngeal carcinoma using helical tomotherapy. Med Dosim. 2012:37(1):92-7.

20. Jin X, Han C, Zhou Y, Yi J, Yan H, Xie C. A modified VMAT adaptive radiotherapy for nasopharyngeal cancer patients based on CT-CT image fusion. Radiat Oncol. 2013;8:277.

21. Schwartz DL, Garden AS, Shah SJ, Chronowski G, Sejpal S, Rosenthal DI, et al. Adaptive radiotherapy for head and neck cancer--dosimetric results from a prospective clinical trial. Radiother Oncol. 2013;106(1):80-4.

22. Tan W, Li Y, Han G, Xu J, Wang X, Li Y, et al. Target volume and position variations during intensity-modulated radiotherapy for patients with nasopharyngeal carcinoma. Onco Targets Ther. 2013;6:1719-28.

23. Fung WW, Wu WW, Teo PM. Developing an adaptive radiation therapy strategy for nasopharyngeal carcinoma. J Radiat Res. 2014;55(2):293-304.

24. Huang $H$, Lu H, Feng $G$, Jiang $H$, Chen J, Cheng J, et al. Determining appropriate timing of adaptive radiation therapy for nasopharyngeal carcinoma during intensity-modulated radiation therapy. Radiat Oncol. 2015;10:192.

25. Kataria T, Gupta D, Goyal S, Bisht SS, Basu T, Abhishek A, et al. Clinical outcomes of adaptive radiotherapy in head and neck cancers. Br J Radiol. 2016;89(1062):20160085

26. Zhang P, Simon A, Rigaud B, Castelli J, Ospina Arango JD, Nassef M, et al. Optimal adaptive IMRT strategy to spare the parotid glands in oropharyngeal cancer. Radiother Oncol. 2016;120(1):41-7.

27. Surucu M, Shah KK, Roeske JC, Choi M, Small W Jr, Emami B. Adaptive radiotherapy for head and neck Cancer. Technol Cancer Res Treat. 2017;16(2):218-23.

28. Tan W, Wang Y, Yang M, Amos RA, Li W, Ye J, et al. Analysis of geometric variation of neck node levels during image-guided radiotherapy for nasopharyngeal carcinoma: recommended planning margins. Quant Imaging Med Surg. 2018;8(7):637-47.

29. Wang W, Yang H, Hu W, Shan G, Ding W, Yu C, et al. Clinical study of the necessity of replanning before the 25th fraction during the course of intensity-modulated radiotherapy for patients with nasopharyngeal carcinoma. Int J Radiat Oncol Biol Phys. 2010;77(2):617-21.

30. Lin A, Kim HM, Terrell JE, Dawson LA, Ship JA, Eisbruch A. Quality of life after parotid-sparing IMRT for head-and-neck cancer: a prospective longitudinal study. Int J Radiat Oncol Biol Phys. 2003;57(1):61-70.

31. Eisbruch A, Ten Haken RK, Kim HM, Marsh LH, Ship JA. Dose, volume, and function relationships in parotid salivary glands following conformal and intensity-modulated irradiation of head and neck cancer. Int J Radiat Oncol Biol Phys. 1999;45(3):577-87.

32. Miah AB, Schick U, Bhide SA, Guerrero-Urbano MT, Clark CH, Bidmead AM, et al. A phase II trial of induction chemotherapy and chemo-IMRT for head and neck squamous cell cancers at risk of bilateral nodal spread: the application of a bilateral superficial lobe parotid-sparing IMRT technique and treatment outcomes. Br J Cancer. 2015;112(1):32-8.

33. Miah AB, Gulliford SL, Morden J, Newbold KL, Bhide SA, Zaidi SH, et al. Recovery of salivary function: contralateral parotid-sparing intensity-modulated radiotherapy versus bilateral superficial lobe parotid-sparing intensitymodulated radiotherapy. Clin Oncol (R Coll Radiol). 2016;28(9):e69-76.

34. Zhang $Y$, Lin C, Wu J, Jiang $X$, Lee SWY, Tam SY, et al. A longitudinal evaluation of early anatomical changes of parotid gland in intensity modulated radiotherapy of nasopharyngeal carcinoma patients with parapharyngeal space involvement. J Med Radiat Sci. 2017;64(3):188-94.

35. Hunter KU, Fernandes LL, Vineberg KA, McShan D, Antonuk AE, Cornwall C, et al. Parotid glands dose-effect relationships based on their actually delivered doses: implications for adaptive replanning in radiation therapy of head-and-neck cancer. Int J Radiat Oncol Biol Phys. 2013;87(4):676-82.

36. Yao WR, Xu SP, Liu B, Cao XT, Ren G, Du L, et al. Replanning criteria and timing definition for parotid protection-based adaptive radiation therapy in nasopharyngeal carcinoma. Biomed Res Int. 2015;2015:476383.

37. Bahig H, Yuan Y, Mohamed ASR, Brock KK, Ng SP, Wang J, et al. Magnetic resonance-based response assessment and dose adaptation in human papilloma virus positive tumors of the oropharynx treated with radiotherapy (MR-ADAPTOR): an R-IDEAL stage 2a-2b/Bayesian phase II trial. Clin Transl Radiat Oncol. 2018;13:19-23.

38. Castelli J, Simon A, Rigaud B, Lafond C, Chajon E, Ospina JD, et al. A Nomogram to predict parotid gland overdose in head and neck IMRT. Radiat Oncol. 2016;11:79.
39. Pukala J, Staton R, Langen K. SU-E-J-201: What is the Importance of Dose Recalculation for Adaptive Radiotherapy Dose Assessment? Med Phys. 2012; 39(6Part9):3699.

40. Hu YC, Tsai KW, Lee CC, Peng NJ, Chien JC, Tseng HH, et al. Which nasopharyngeal cancer patients need adaptive radiotherapy? BMC Cancer 2018;18(1):1234.

41. Fiorentino A, Caivano R, Metallo V, Chiumento C, Cozzolino M, Califano G, et al. Parotid gland volumetric changes during intensity-modulated radiotherapy in head and neck cancer. Br J Radiol. 2012;85(1018):1415-9.

42. Hansen EK, Bucci MK, Quivey JM, Weinberg V, Xia P. Repeat CT imaging and replanning during the course of IMRT for head-and-neck cancer. Int J Radiat Oncol Biol Phys. 2006;64(2):355-62.

43. Wu Q, Chi Y, Chen PY, Krauss DJ, Yan D, Martinez A. Adaptive replanning strategies accounting for shrinkage in head and neck IMRT. Int J Radiat Oncol Biol Phys. 2009:75(3):924-32.

44. Zhao L, Wan Q, Zhou Y, Deng X, Xie C, Wu S. The role of replanning in fractionated intensity modulated radiotherapy for nasopharyngeal carcinoma. Radiother Oncol. 2011;98(1):23-7.

45. ClinicalTrials.gov. Evaluation of the automatic deformable recontouring on the daily MVCT for head and neck cancer adaptive radiotherapy (GIRAFE) (NCT03953352). Bethesda: National Library of Medicine (US); 2019. [updated 7/25/2019. Available from: https://clinicaltrials.gov/ct2/show/NCT03953352

46. Kirkpatrick JP, van der Kogel AJ, Schultheiss TE. Radiation dose-volume effects in the spinal cord. Int J Radiat Oncol Biol Phys. 2010;76(3 Suppl):S42-9.

47. Ding Y, Hazle JD, Mohamed AS, Frank SJ, Hobbs BP, Colen RR, et al. Intravoxel incoherent motion imaging kinetics during chemoradiotherapy for human papillomavirus-associated squamous cell carcinoma of the oropharynx: preliminary results from a prospective pilot study. NMR Biomed. 2015;28(12):1645-54.

48. Mohamed ASR, Bahig H, Aristophanous M, Blanchard P, Kamal M, Ding Y, et al. Prospective in silico study of the feasibility and dosimetric advantages of MRI-guided dose adaptation for human papillomavirus positive oropharyngeal cancer patients compared with standard IMRT. Clin Trans| Radiat Oncol. 2018;11:11-8.

49. Hamming-Vrieze $\mathrm{O}$, van Kranen SR, Heemsbergen WD, Lange CAH, van den Brekel MWM, Verheij M, et al. Analysis of GTV reduction during radiotherapy for oropharyngeal cancer: implications for adaptive radiotherapy. Radiother Oncol. 2017;122(2):224-8.

50. ClinicalTrials.gov. A prospective non-inferiority trial of the use of adaptive radiotherapy for head and neck cancer undergoing radiation therapy (NCT03096808). Bethesda: National Library of Medicine (US); 2019. [updated 5/27/2019. Available from: https://clinicaltrials.gov/ct2/show/NCT03096808

51. Brouwer CL, Steenbakkers RJ, van der Schaaf A, Sopacua CT, van Dijk LV, Kierkels RG, et al. Selection of head and neck cancer patients for adaptive radiotherapy to decrease xerostomia. Radiother Oncol. 2016;120(1):36-40.

52. Brown E, Owen R, Harden F, Mengersen K, Oestreich K, Houghton W, et al. Predicting the need for adaptive radiotherapy in head and neck cancer. Radiother Oncol. 2015;116(1):57-63.

53. Vickress JR, Battista J, Barnett R, Yartsev S. Online daily assessment of dose change in head and neck radiotherapy without dose-recalculation. J Appl Clin Med Phys. 2018;19(5):659-65.

54. Wagenblast S, Kampfer S, Borm KJ, Combs SE, Pigorsch SU, Duma MN. CTbased dose recalculations in head and neck cancer radiotherapy: comparison of daily dose recalculations to less time-consuming approaches. Strahlenther Onkol. 2019;195(6):475-81.

55. Schwartz DL, Garden AS, Thomas J, Chen Y, Zhang Y, Lewin J, et al. Adaptive radiotherapy for head-and-neck cancer: initial clinical outcomes from a prospective trial. Int J Radiat Oncol Biol Phys. 2012;83(3):986-93.

56. Aly F, Miller AA, Jameson MG, Metcalfe PE. A prospective study of weekly intensity modulated radiation therapy plan adaptation for head and neck cancer: improved target coverage and organ at risk sparing. Australas Phys Eng Sci Med. 2019;42(1):43-51.

57. Hu CC, Huang WT, Tsai CL, Wu JK, Chao HL, Huang GM, et al. Practically acquired and modified cone-beam computed tomography images for accurate dose calculation in head and neck cancer. Strahlenther Onkol. 2011;187(10):633-44.

58. Lu W, Yan H, Gu X, Tian Z, Luo O, Yang L, et al. Reconstructing cone-beam $\mathrm{CT}$ with spatially varying qualities for adaptive radiotherapy: a proof-ofprinciple study. Phys Med Biol. 2014;59(20):6251-66.

59. Liu C, Kim J, Kumarasiri A, Mayyas E, Brown SL, Wen N, et al. An automated dose tracking system for adaptive radiation therapy. Comput Methods Prog Biomed. 2018;154:1-8. 
60. Esteyrie V, Gleyzolle B, Lusque A, Graff P, Modesto A, Rives M, et al. The GIRAFE phase II trial on MVCT-based "volumes of the day" and "dose of the day" addresses when and how to implement adaptive radiotherapy for locally advanced head and neck cancer. Clin Transl Radiat Oncol. 2019;16:34-9.

61. Halmos GB, Bruine de Bruin L, Langendijk JA, van der Laan BF, Pruim J, Steenbakkers RJ. Head and neck tumor hypoxia imaging by 18 F-fluoroazomycinarabinoside (18F-FAZA)-PET: a review. Clin Nucl Med. 2014;39(1):44-8.

62. De Felice F, Thomas C, Barrington S, Pathmanathan A, Lei M, Urbano TG. Analysis of loco-regional failures in head and neck cancer after radical radiation therapy. Oral Oncol. 2015;51(11):1051-5.

63. Chen AM, Chin R, Beron P, Yoshizaki T, Mikaeilian AG, Cao M. Inadequate target volume delineation and local-regional recurrence after intensitymodulated radiotherapy for human papillomavirus-positive oropharynx cancer. Radiother Oncol. 2017;123(3):412-8.

64. de Ridder M, Gouw ZAR, Sonke JJ, Navran A, Jasperse B, Heukelom J, et al. Recurrent oropharyngeal cancer after organ preserving treatment: pattern of failure and survival. Eur Arch Otorhinolaryngol. 2017;274(3):1691-700.

65. Ling CC, Humm J, Larson S, Amols H, Fuks Z, Leibel S, et al. Towards multidimensional radiotherapy (MD-CRT): biological imaging and biological conformality. Int J Radiat Oncol Biol Phys. 2000;47(3):551-60.

66. Bentzen SM. Theragnostic imaging for radiation oncology: dose-painting by numbers. Lancet Oncol. 2005;6(2):112-7.

67. Servagi-Vernat S, Differding S, Sterpin E, Hanin FX, Labar D, Bol A, et al. Hypoxia-guided adaptive radiation dose escalation in head and neck carcinoma: a planning study. Acta Oncol. 2015;54(7):1008-16.

68. Duprez F, De Neve W, De Gersem W, Coghe M, Madani I. Adaptive dose painting by numbers for head-and-neck cancer. Int J Radiat Oncol Biol Phys. 2011;80(4):1045-55.

69. Berwouts D, Olteanu LA, Duprez F, Vercauteren T, De Gersem W, De Neve W, et al. Three-phase adaptive dose-painting-by-numbers for head-and-neck cancer: initial results of the phase I clinical trial. Radiother Oncol. 2013; 107(3):310-6.

70. Berwouts D, Madani I, Duprez F, Olteanu AL, Vercauteren T, Boterberg T, et al. Long-term outcome of (18) F-fluorodeoxyglucose-positron emission tomography-guided dose painting for head and neck cancer: matched case-control study. Head Neck. 2017;39(11):2264-75.

71. Olteanu LAM, Duprez F, De Neve W, Berwouts D, Vercauteren T, Bauters W, et al. Late mucosal ulcers in dose-escalated adaptive dose-painting treatments for head-and-neck cancer. Acta Oncol. 2018;57(2):262-8.

72. ClinicalTrials.gov. A Two-arm Phase II Randomized Study, Comparing Adaptive Biological Imaging - Voxel Intensity - Based Radiotherapy (Adaptive Dose Escalation) Versus Standard Radiotherapy for Head and Neck Cancer (C-ART-2) (NCT01341535). Bethesda: National Library of Medicine (US); 2018. [updated 5/21/2018. Available from: https://clinicaltrials. gov/ct2/show/NCT01341535

73. Heukelom J, Hamming O, Bartelink H, Hoebers F, Giralt J, Herlestam T, et al. Adaptive and innovative radiation treatment FOR improving Cancer treatment outcomE (ARTFORCE); a randomized controlled phase II trial for individualized treatment of head and neck cancer. BMC Cancer. 2013;13:84.

74. ClinicalTrials.gov. Phase III Randomized Study With Cisplatinum and Conventional or Adaptive High Dose Radiotherapy for Advanced Head and Neck Cancer (ARTFORCE) (NCT01504815). Bethesda: National Library of Medicine (US); 2017. [updated 9/28/2017. Available from: https://clinicaltrials. gov/ct2/show/NCT01504815

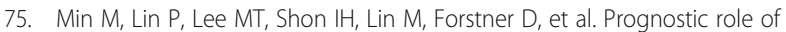
metabolic parameters of (18)F-FDG PET-CT scan performed during radiation therapy in locally advanced head and neck squamous cell carcinoma. Eur J Nucl Med Mol Imaging. 2015;42(13):1984-94.

76. Lin $\mathrm{P}$, Min M, Lee $M$, Holloway L, Forstner D, Bray V, et al. Prognostic utility of (18)F-FDG PET-CT performed prior to and during primary radiotherapy for nasopharyngeal carcinoma: index node is a useful prognostic imaging biomarker site. Radiother Oncol. 2016;120(1):87-91.

77. Min M, Lin P, Lee M, Shon IH, Lin M, Forstner D, et al. 18F-FDG PET-CT performed before and during radiation therapy of head and neck squamous cell carcinoma: are they independent or complementary to each other? J Med Imaging Radiat Oncol. 2016;60(3):433-40.

78. ClinicalTrials.gov. MRI-guided Adaptive RadioTHerapy for reducing xerostomiA in Head and Neck Cancer (MARTHA-trial) (NCT03972072). Bethesda: National Library of Medicine (US); 2019. [updated 6/3/2019. Available from: https://clinicaltrials.gov/ct2/show/NCT03972072?cond= martha+trial\&rank=1
79. ClinicalTrials.gov. ayesian Phase II Trial of Magnetic Resonance Imaging Guided Radiotherapy Dose Adaptation in Human Papilloma Virus Positive Oropharyngeal Cancer (MR-ADAPTOR) (NCT03224000). Bethesda: National Library of Medicine (US); 2019. [updated 7/26/2019. Available from: https:// clinicaltrials.gov/ct2/show/NCT03224000

80. ClinicalTrials.gov. Adaptive, Image-guided, Intensity-modulated Radiotherapy for Head and Neck Cancer in the Reduced Volumes of Elective Neck: a Multicenter, Two-arm, Randomized Phase II Trial (NCT01287390). Bethesda: National Library of Medicine (US); 2016. [updated 1/27/2016. Available from: https://clinicaltrials.gov/ct2/show/NCT01287390

81. Liang X, Chen L, Nguyen D, Zhou Z, Gu X, Yang M, et al. Generating synthesized computed tomography (CT) from cone-beam computed tomography (CBCT) using CycleGAN for adaptive radiation therapy. Phys Med Biol. 2019;64(12):125002.

\section{Publisher's Note}

Springer Nature remains neutral with regard to jurisdictional claims in published maps and institutional affiliations.
Ready to submit your research? Choose BMC and benefit from:

- fast, convenient online submission

- thorough peer review by experienced researchers in your field

- rapid publication on acceptance

- support for research data, including large and complex data types

- gold Open Access which fosters wider collaboration and increased citations

- maximum visibility for your research: over $100 \mathrm{M}$ website views per year

At BMC, research is always in progress.

Learn more biomedcentral.com/submissions 